\title{
Mechanism Research on PM2.5 Charging, Precipitation in High Electrostatic Field
}

\author{
Jingcai Chang1, Chunyan Xu1, Aiping Tao², Mingfeng Gao², Xiang Wang1, Chunyuan Ma1 \\ ${ }^{1}$ Shandong University, Jinan, China \\ ${ }^{2}$ China Huadian Corporation, Beingjing, China \\ Email: changjingcai@126.com, zcxcyid@163.com, taoaip@chec.com.cn, gaomf@chec.com.cn, \\ 570910051@qq.com, chym@sdu.edu.cn
}

Received 11 December 2014; accepted 25 December 2014; published 14 January 2015

Copyright (C) 2015 by authors and Scientific Research Publishing Inc.

This work is licensed under the Creative Commons Attribution International License (CC BY).

http://creativecommons.org/licenses/by/4.0/

(c) (i) Open Access

\section{Abstract}

In this project, some charged characteristics, and analysis of precipitated PM2.5 in high electrostatic field were calculated based on theories and experiments. The connection between the charge amount and the additional electric field intensity caused by the wet flexible collectors was studied to reveal the mechanism of charging enhancement of PM2.5 on flexible collectors. Some explanation about the wet ability of collectors and the current density enhancing the precipitation process was proposed in this project. Simultaneously, the results shows that both gas treatment time and applied voltage have an important influence on particle collection, and the minor factor was initial concentration.

\section{Keywords}

PM2.5, Charging, Precipitation, Electrostatic Precipitator

\section{Introduction}

Particle matter (PM) in air can lead to secondary aerosols absorbing various harmful compounds [1] [2]. Wet electrostatic precipitators (ESPs) have been developed and tested which had exhibited good control of fine particles because of increasing the cohesive forces between the aerosol particles and the water film [3] [4]. However, in most wet ESPs, there are channeling and other non-uniform flow problems on traditional rigid collection electrodes surface. This would reduce current flow and lower overall precipitator's efficiency [5]. It has been concluded the overall $V$-I curve of composite fibrous materials was higher compared with the typical rigid collector using a thimbleful of water penetrating them [6]. As a result, current could be increased obviously to enhance the collection efficiency by fabrics collectors [7]. 
In this project, a new wet electrostatic precipitator had been evaluated for its effectiveness as an alternative control of particulate emissions. Particles collection consisted of three stages; charging the particles; collecting the charged particles on the collector; and cleaning. The connection between the charge amount and the additional electric field intensity caused by the wet flexible collectors was studied to reveal the mechanism of charging enhancement of PM2.5. The use of fabrics collection electrodes would offer the following advantages: Minor water addition rate, excellent corrosion resistant, low maintenance requirements, simplicity in operation, and uninterruptible power flushing.

\section{Experimental}

\subsection{Experimental Setup}

The experimental setup for this study was shown in Figure 1. It consisted of a detection system, test duct section, DC power supply system, and an ESP equipped with fabrics collectors. An aerosol feeding device (SAG-410) aerosolized the test particles from storage tank at a predetermined rate. The air entering the device at a negative pressure was deduced by an induced draft. The distance between two collectors was $400 \mathrm{~mm}$, the ESP crosssectional area was $0.32 \mathrm{~m}^{2}$, and the length of the collectors was $4 \mathrm{~m}$. A patented integrated system with water distribution and tension functions for polypropylene fibrous collectors (Patent No.: CN200910019222.7) was installed in the ESP. Gases flowed from right to left via deflectors which was guided by numerical simulation results, respectively. The gas residence time was $1.1 \sim 3.33 \mathrm{~s}$. A DC voltage controller was used, and the applied voltage was in the range of $25 \sim 70 \mathrm{kV}$, thus the electric field strength was $0.275 \sim 0.35 \mathrm{kV} / \mathrm{cm}$. The temperature was in the range of $325 \sim 330 \mathrm{~K}$ (measured by type $\mathrm{K}$ thermocouples), respectively. The high-voltage electrodes were barbed wires which could produce more gaseous ions at high negative potential.

\subsection{Test Particles}

The industrial smoke dust was screened to obtain test particles by electromagnetic high frequency vibrating screen. A real-time detection system (ELPI) was used to measure the variety of the number concentration under several conditions. Figure 2 shows the size distribution of fine particles, the predetermined mass concentrations were controlled by frequency modulator of SAG which was earlier calibrated by dust meter $(3012 \mathrm{H})$. They are charged particles from 0.05 to $<2.5 \mu \mathrm{m}$ in size. Electrical effects can predominate as transport and deposition mechanism for particles $<1 \mu \mathrm{m}$ in size. The greater the charge they possess the higher deposition.

\section{Results and Discussions}

\subsection{Current Density of Polypropylene Fibrous Collector}

The overall current density curve of polypropylene fibrous collector was carried out to obtain electric behavior using negative high-voltage DC power as shown in Figure 3. The current density increased sharply when the applied voltage increased from $10 \mathrm{kV}$ to $60 \mathrm{kV}$ until the blue filaments or spark-over were visible. These measurements were carried out with various secondary voltages. A nameplate indicating primary voltage, primary current, secondary voltage, secondary current, power consumption, etc. were located on the front of the low vol-

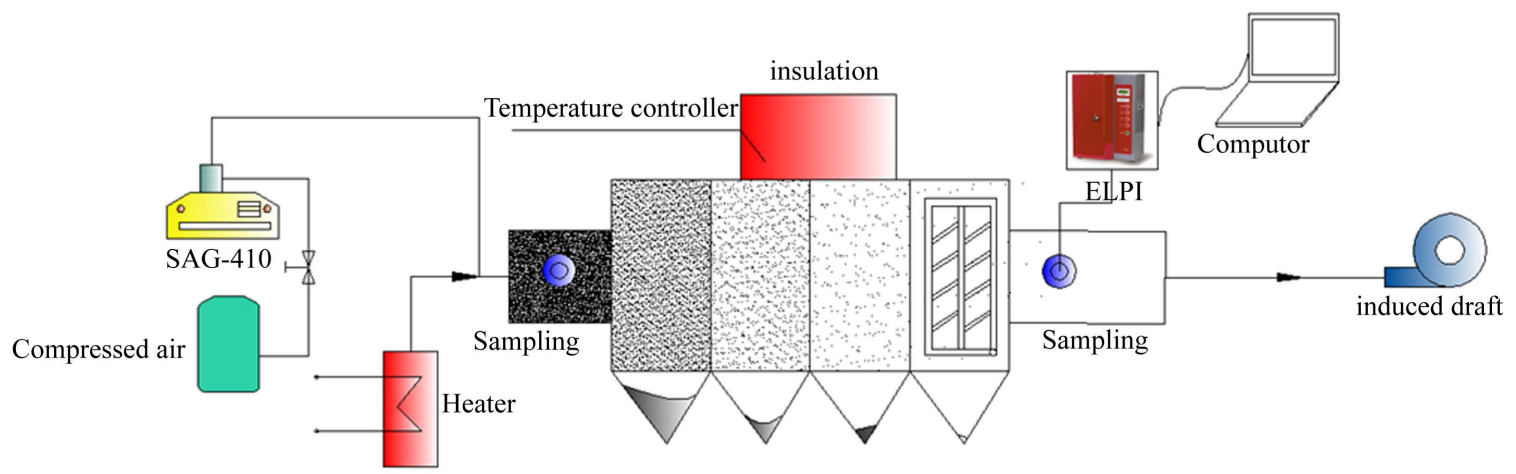

Figure 1. Schematic diagram of the experimental setup. 


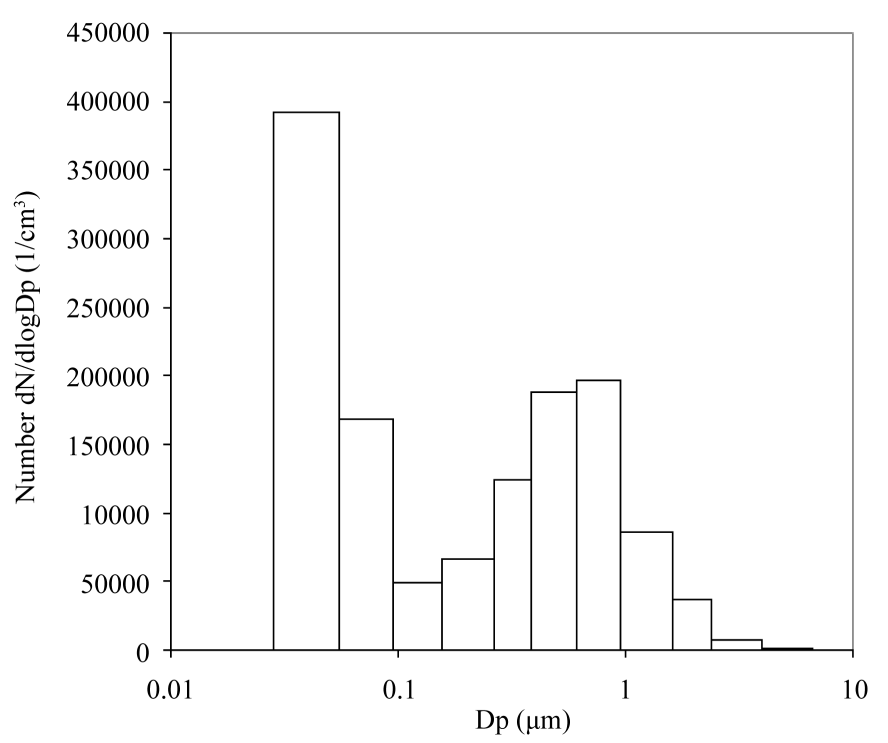

Figure 2. Characteristics of number distribution of submicron particles in experiments.

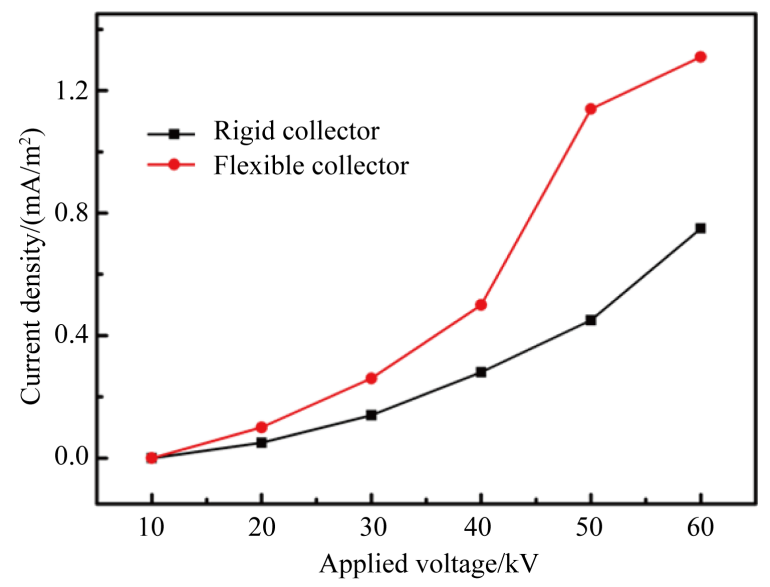

(a)

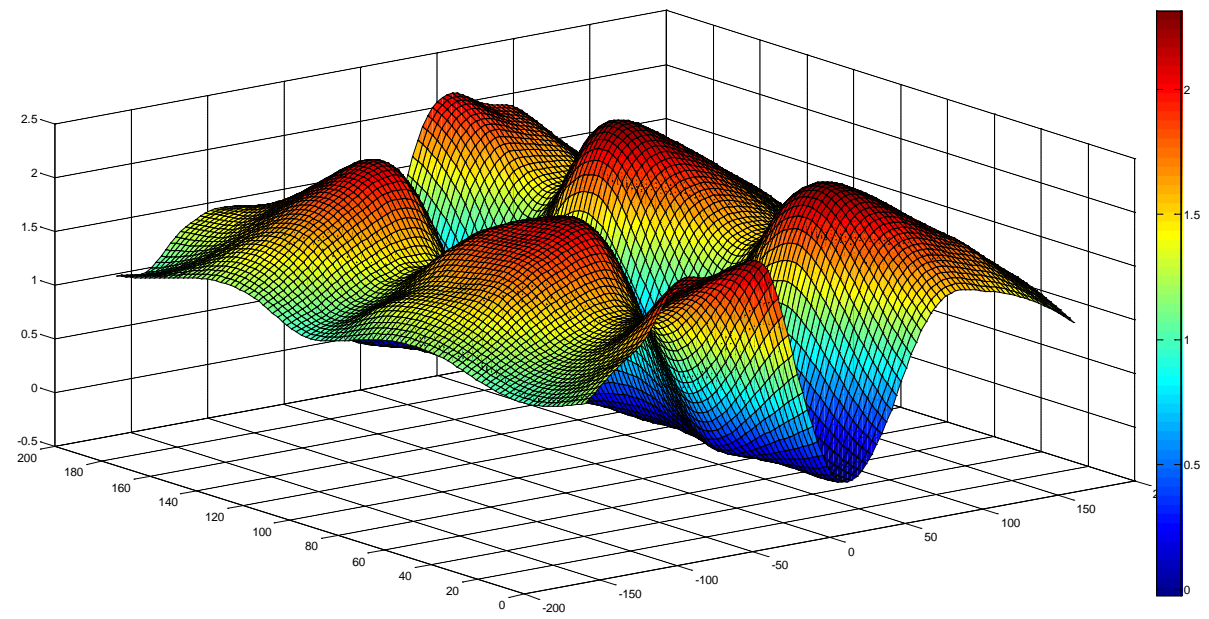

(b)

Figure 3. Current density characteristics of flexible collector. (a) Current density as a function of voltage; (b) Space distribution of current density. 
tage panel. The maximum working voltage was ensured under above-mentioned conditions. Figure 3 shows a similar tendency of discharge current density for flexible collector and rigid steel collector. The current density by flexible collector was $20 \sim 100$ percent higher than that by rigid collector as illustrated in Table 1 . Higher stronger electric field resulted in higher discharge current. Even though the initial collectors are insulated before water penetrating them via capillary flow, it could be demonstrated that flexible collector wetted was consistent with the behavior of conventional rigid steel collector in electric field. The current density by flexible collectors were increased which would help to precipitate PM2.5 more easily than conventional steel materials.

\subsection{Particle Collection Efficiency}

The concentration of particles entering the ESP, $C_{\text {in }}$, and the concentration of particles leaving the ESP, $C_{\text {out }}$, were monitored by Electrical Low Pressure Impactor (ELPI). Thus, the collection efficiency could be derived as:

$$
\eta=\frac{C_{\text {in }}-C_{\text {out }}}{C_{\text {in }}} \times 100 \%
$$

where $\eta$ is the collection efficiency, $C_{\text {in }}$ is the initial number concentration of fine particles, and $C_{\text {out }}$ is the final number concentration at the outlet of the improved wet ESP.

As illustrated in Figure 2, the number concentration at the outlet was strongly influenced by both gas velocity and applied voltage. The higher applied voltage or lower gas velocity, the lower concentration at the outlet would be. Figure 2 shows initial number concentration with zero voltage at setting feeding frequency via experimental duration. Its final number concentration depends on the secondary voltage and its initial values. After particles injected into the device by SAG, the number concentration decreased rapidly after about $1 \mathrm{~s}$. As illustrated in Figure 4, the number distribution of submicron particles decreased rapidly. The results show that the

\begin{tabular}{|cccc}
\hline \multicolumn{4}{c}{ Table 1. Parameters of current density characteristics for flexible and rigid collector. } \\
\hline Applied voltage $(\mathrm{kV})$ & Rigid $\left(\mathrm{mA} \cdot \mathrm{m}^{-2}\right)$ & Flexible $\left(\mathrm{mA} \cdot \mathrm{m}^{-2}\right)$ & $\mathrm{I}_{\mathrm{F}} / \mathrm{I}_{\mathrm{R}}$ \\
\hline 10 & 0 & 0 & $/$ \\
20 & 0.05 & 0.10 & 2.00 \\
30 & 0.14 & 0.26 & 1.86 \\
40 & 0.28 & 0.50 & 1.79 \\
50 & 0.45 & 1.14 & 2.53 \\
60 & 0.75 & 1.31 & 1.75 \\
\hline
\end{tabular}

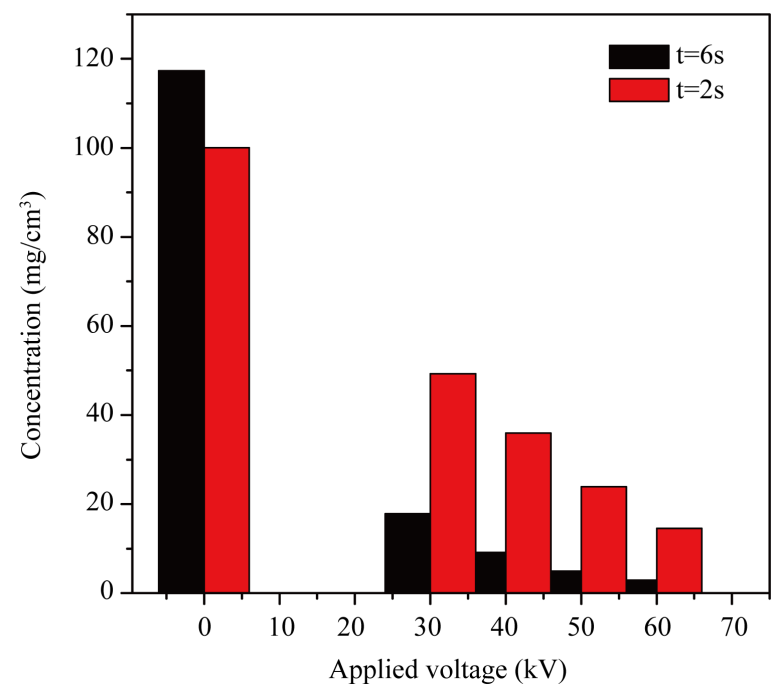

Figure 4. Effects of gas treatment time on the efficiency. 
overall efficiency curves had similar curvilinear trend under various working conditions. As illustrated in Figure 5 , there was not obvious link between initial concentration and collection efficiencies, the efficiencies at higher inlet concentration or lower concentration by flexible collectors were almost the same. The average number collection efficiencies by flexible collector amounted to $88.3 \%$ for PM2.5 when the gas residence time was $4 \mathrm{~s}$ at $60 \mathrm{kV}$ as shown in Figure 6. It could be conclude that flexible collectors allowed the current to be higher, and the collection efficiencies, especially for fine particles, were also higher. An increase in applied voltage was presumably caused higher charge for PM2.5 particles, thus would be beneficial to offer better collection efficiency. It can be concluded that the number efficiency was higher with higher applied voltage than that with lower applied voltage for particles in the same gas treatment time. The higher performance of flexible collectors indicated that they could be popularized to applications, thus would be propitious to solve cool-end corrosion and extra water consumptions problems.

\subsection{Effects of Water Film on Particle Agglomeration}

The effects of water film on particle agglomeration in gas were investigated. Agglomeration is a process in which smaller particles adhere to a larger one, or in which smaller particles come together to form a larger one. As shown in Figure 7, the effect of water film evaporation on decreasing the number concentration was of great

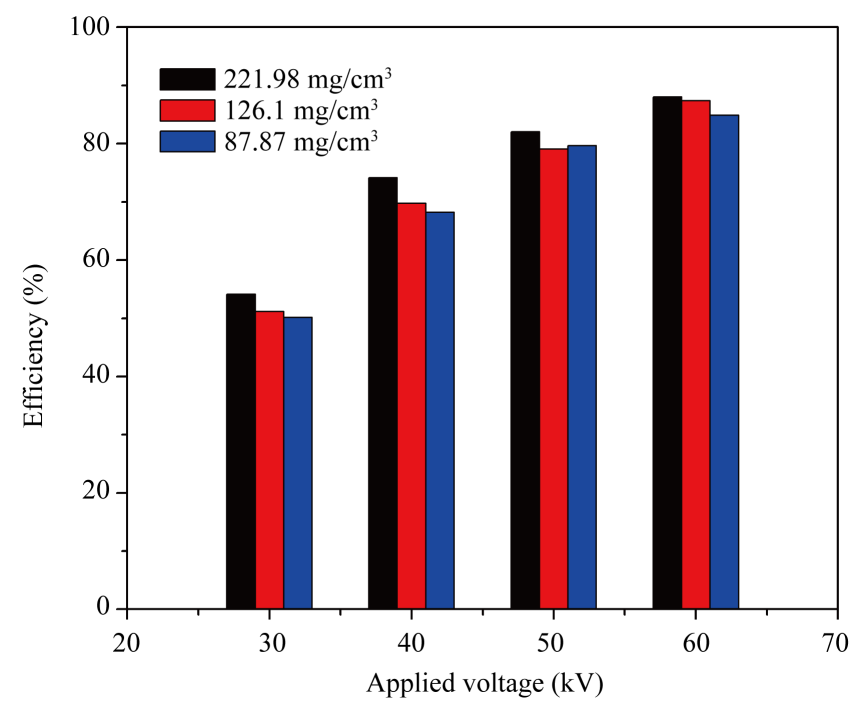

Figure 5. Effects of initial concentration on the efficiency.

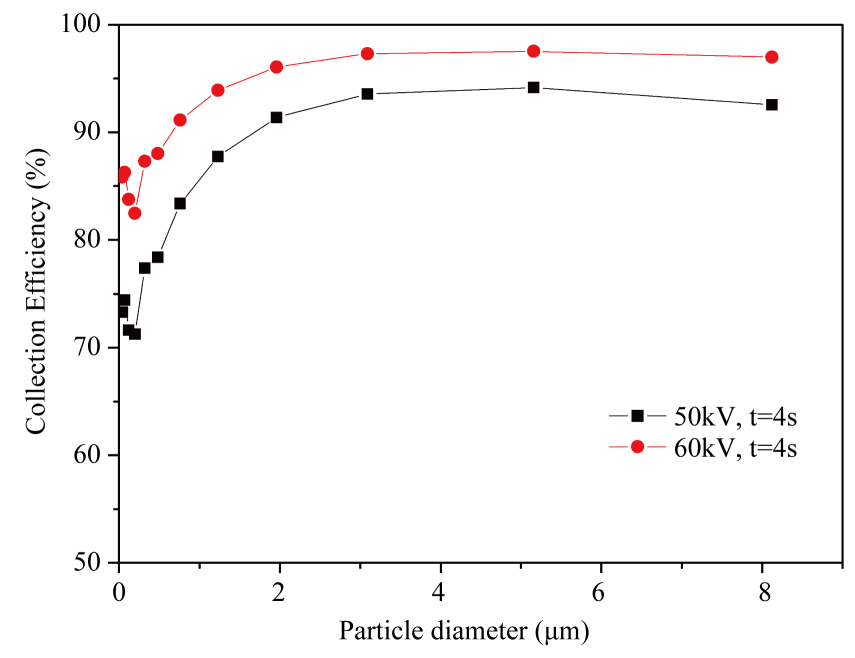

Figure 6. Effects of applied voltage on the removal of fine particles. 


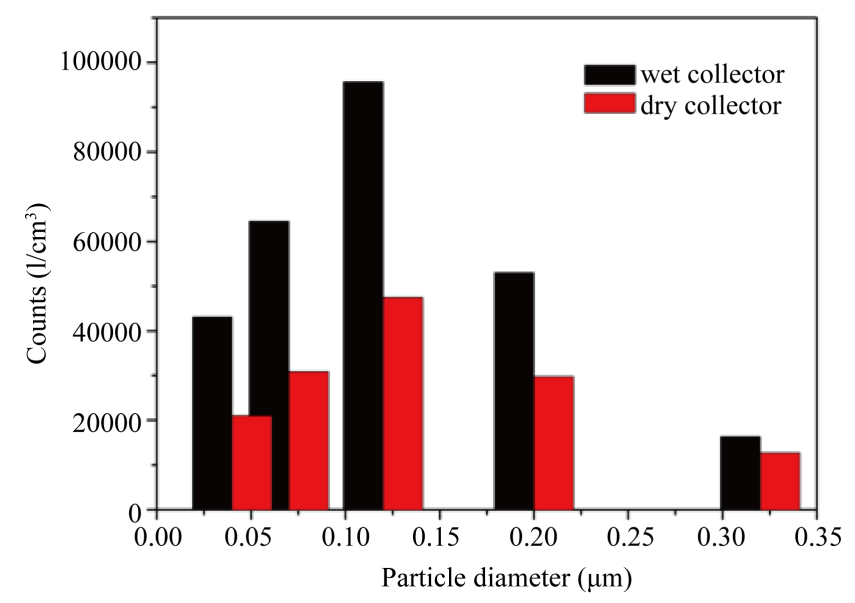

Figure 7. Effects of water film on the particles agglomeration.

significance to particles agglomeration. Meanwhile, the number concentration of fine particles $(<0.5 \mu \mathrm{m})$ declined substantially, and all repeated test indicated that there was significant effect on the particle agglomeration for wet collectors in gas. Furthermore, the maximum water evaporation addition rate was $25 \mathrm{~L} /\left(\mathrm{h} \cdot \mathrm{m}^{2}\right)$ when the gas velocity was $3 \mathrm{~m} / \mathrm{s}$, respectively. It could be calculated that the decrease of the number concentration was not less than $40 \%$ for ultrafine particles $(<0.5 \mu \mathrm{m})$ depend on the water film adsorption. In other words, the effect of water film adsorption on the temperature drop was more sensible. Meanwhile, it could be observed that as long as there was any water on the surface, any particle would exhibit similar agglomeration, whether at higher or smaller water addition rate. It could be concluded that the flexible collectors could maintain uniform wetting property and excellent adsorption via capillary penetration consuming smaller water, thus would allow lower water consumption in the applications.

\section{Summary}

The experiment was designed to investigate the mechanism on PM2.5 charging, precipitation in high electrostatic field. The connection between the charge amount and the additional electric field intensity caused by the wet flexible collectors was studied. The results show that the current density by flexible collector was $20 \sim 100$ percent higher than that by rigid collector. The current density by flexible collectors were increased which would help to precipitate PM2.5 more easily than conventional steel materials. There was not obvious link between initial concentration and collection efficiencies, and the efficiencies at higher inlet concentration or lower concentration by flexible collectors were almost the same. The average number collection efficiencies by flexible collector amounted to $88.3 \%$ for PM2.5 when the gas residence time was $4 \mathrm{~s}$ at $60 \mathrm{kV}$. The number concentration of fine particles $(<0.5 \mu \mathrm{m})$ declined substantially, and all repeated test indicated that there was significant effect for wet flexible collectors on the particle agglomeration in gas. The decrease of the number concentration was not less than $40 \%$ for ultrafine particles $(<0.5 \mu \mathrm{m})$ depend on the water film adsorption.

\section{References}

[1] Zhang, G.X., Liu, J.Z., Zhou, J.H., Wang, J. and Cen, K.F. (2009) Proceedings of the CSEE, 29, 97-102.

[2] Ellasson, B., Egli, W., Ferguson, J.R. and Jodeit, H. (1987) Coagulation of Bipolarly Charged Aerosols in a Stack Coagulator. Journal of Aerosol Science, 18, 869-872. http://dx.doi.org/10.1016/0021-8502(87)90143-1

[3] Jaworek, A., Krupa, A. and Czech, T. (2007) Modern Electrostatic Devices and Methods for Exhaust Gas Cleaning: A Brief Review. Journal of Electrostatics, 65, 133-155. http://dx.doi.org/10.1016/j.elstat.2006.07.012

[4] Ellasson, B., Egli, W., Ferguson, J.R. and Jodeit, H. (1987) Coagulation of Bipolarly Charged Aerosols in a Stack Coagulator. Journal of Aerosol Science, 18, 869-872. http://dx.doi.org/10.1016/0021-8502(87)90143-1

[5] Bayless, D.J., Alam, M.K. and Caine, R.J. (2004) Membrane-Based Wet Electrostatic Precipitation. Fuel Processing Technology, 85, 781-798. http://dx.doi.org/10.1016/j.fuproc.2003.11.025

[6] Batch, G.L., Chen, Y.T. and Macoskot, C.W. (1996) Journal of Reinforced Plastics and Composites, $15,1027$.

[7] Chang, J.C., Dong, Y., Wang, Z.Q., Wang, P., Chen, P. and Ma, C.Y. (2011) Journal of Aerosol Science, 42, $544-554$. 
Scientific Research Publishing (SCIRP) is one of the largest Open Access journal publishers. It is currently publishing more than 200 open access, online, peer-reviewed journals covering a wide range of academic disciplines. SCIRP serves the worldwide academic communities and contributes to the progress and application of science with its publication.

Other selected journals from SCIRP are listed as below. Submit your manuscript to us via either submit@scirp.org or Online Submission Portal.
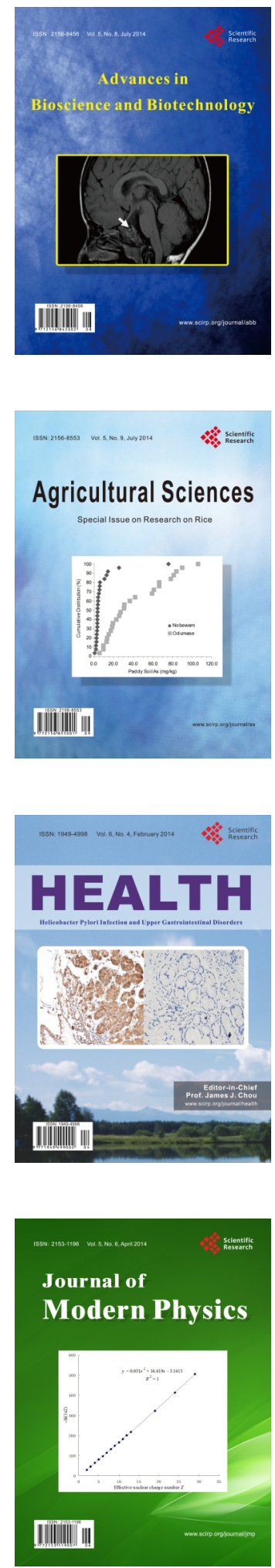
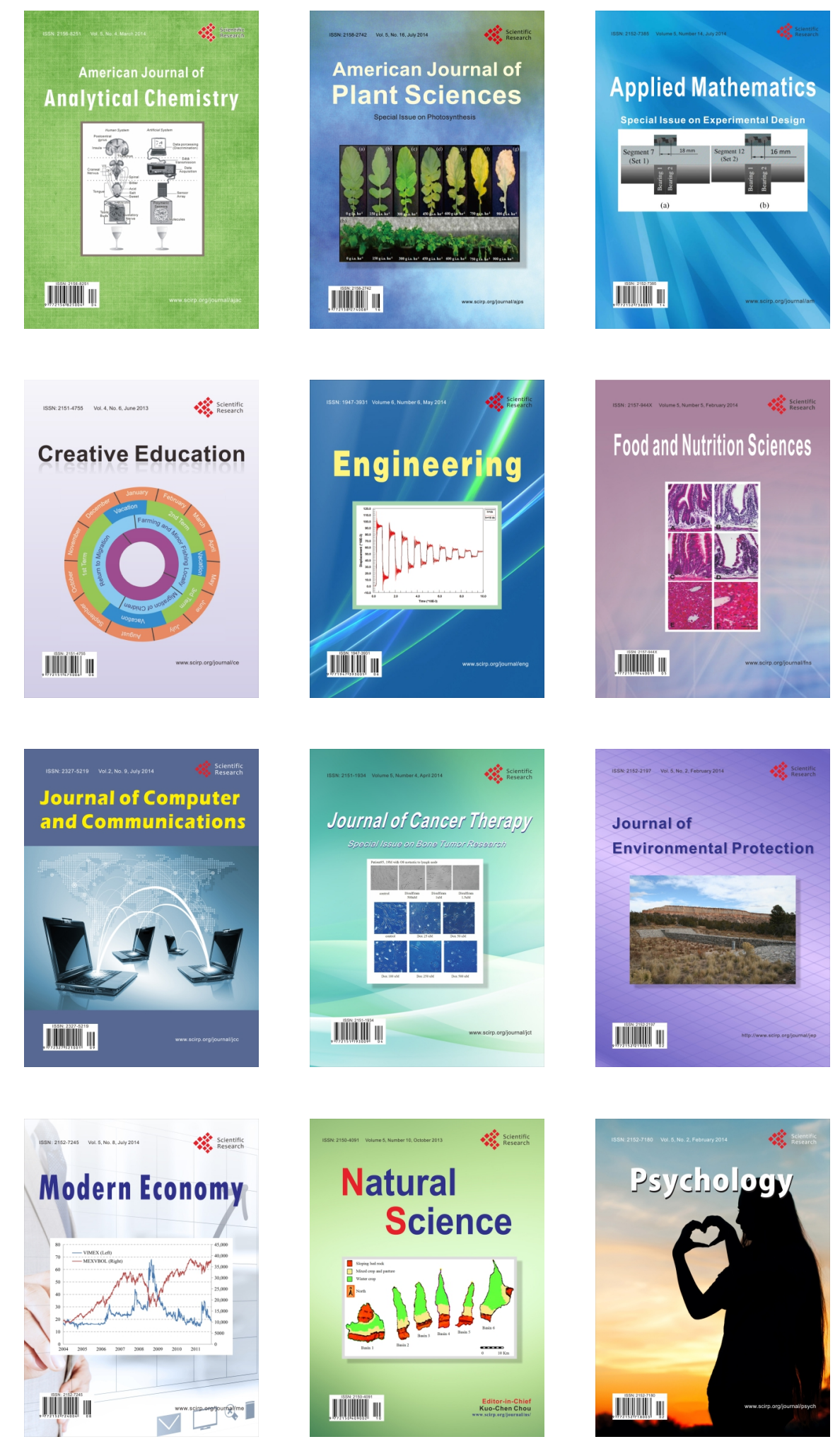